\title{
O MELHOR SYSTEMA TRIBUTARIO
}

\section{QUESTÃ̃ :}

\section{QUAL O MELHOR SYSTEMA TRIBUTARIO}

Summa sequar fatigia rerum. Prospectiones fiunt e turribus.

1) Tendo sido eu forçado a escrever sobre as tres matérias que compõem a secção, havendo disposto de curto espaço de tempo para tal empreza, quando é certo que, noutras secções, ha sómente duas matérias, ou mesmo uma unica, dada ainda a circumstancia de me haver eu especializado, ha pouco, em matérias difficeis, quaes as disciplinas das cadeiras a que concorro, e, emfim, levando-se em consideração minhas condições personalissimas que me embaraçam o rapido estudo, ouso esperar sejam esses factos partes para se me dispensar benevolencia na crítica do que apresento como contribuição para a cultura de um dos mais prementes problemas das sociedades modernas. Resolvi dar a meu trabalho um cunho de synthese, forçado a isso pela exiguidade do tempo, mas reconheço que foi uma difficuldade a mais que me impuz, ao considerar que a matéria é de molde a escapar ás regras geraes, como bem ensina Nitti, nótavel professor de Sciencia das Finanças na Unniversidade de Napoles (Principios da Sciencia 
das Finanças), quando diz, tratando dos systemas de impostos: "Tout pays a sur ce point, on peut le dire, ses institutions particulières" (Trad. de Chamard). Póde-se até dizer que um dos mais arduos problemas relativamente a impostos é reduzir a regras geraes as diversas empiricas, que, sobre tal matéria, têm sido formuladas. No estudo do assumpto, buscarei os principios scientificos que presidem ao desenvolvimento do instituto do imposto, e, em seguida, inspirando-me nestes principios, indagarei quaes as regras mais geraes que sobre a applicação do imposto ao corpo social possam ser consagradas como acudindo ás necessidades do Estado actual.

2) Nos primordios da sociedade, diz Alberto Delatour (Dicc. das Finanças, sob a direcção de Léon Say), quando as despezas que comporta o exercicio do poder são ainda pouco consideraveis o rendimento do dominio pessoal do chefe basta para as satisfazer, e então ainda não apparece o imposto. Por pouco que se desenvolva a sociedade, torna-se necessario que todos, ou alguns, contribuam para o sustento da communhão, sem que se cogite ainda de boa e juséa repartição ${ }^{\circ}$ do encargo pelos membros da sociedade.

Só muito mais tarde, sob a pressão das idéas liberaes, é que o imposto é objecto de estudo scientifico, procurandose justifical-o e descobrir os principios scientificos que o regulam. $\mathrm{O}$ arbitrio, quanto á applicação de impostos, dominou sempre nas sociedades antigas, como vemos pelo que estudamos da revolta do povo judeu ao tempo da morte de Salomão e da separação das tribus, e pelo que nos diz a Historia romana sobre o secesso da plebe que se acalmou com o sophistico apologo de Menenio Agripa. René Stourm cita a affirmação de Hyppolito de Passy, que diz que Roma foi a sociedade antiga que teve maior variedade de impostos. Fóra o que pagamos modernamente de taxa postal, não ha contribuição moderna que não houvesse sido conhecida pelo povo do imperio romano. No fim do se- 
culo XVII, Vauban e Boisguilbert iniciaram o trabalho de busca de regras de justiça á applicação dos impostos.

Logo depois, foi a questão debatida, em França, por Quesnay, Turgot e pelos physiocratas. Na Allemanha occupam-se da matéria Justi e David Hume. Em 1776, Adam Smith formúla as quatro conhecidissimas e sempre citadas regras, que, embora de pequeno valor ou de pequena importancia systematizadora, representam o caminho seguido geralmente pelos governos modernos bem intencionados. Como é sabido, a revolução francesa, reconhecendo que a queixa do povo francês era fundadissima quanto á distribuição dos impostos, fez sobre o instituto social uma reforma radical. A Assembléa constituinte extinguiu todos os antigos impostos, e organizou um systema de contribuições baseado na necessidade que lhe parecia clara de alcançar directamente as rendas. Cada um deveria pagar segundo seus rendimentos, eis o principio fundamental, que não foi por muito tempo observado, pois logo o $\mathrm{Di}$ rectorio creou o monopolio da polvora, o Consulado restabeleceu o imposto sobre as bebidas, e o Imperio tornou a imposto conhecidissimo sobre o sal, o mais celebre e impopular, a crer nos historiadores que se occupam das causas da grande revolução. O certo porém é que, como diz Delatour, acima citado, e que nos vae servindo de guia, hoje temos regnas scientificas sobre o imposto, regras ante as quaes se ha de curvar o legislador que quizer ser digno deste nome. A arte de lançar impostos, ou o lançamento de impostos de accordo com os principios scientificos é dos mais arduos assumptos que se apresentam no governo de uma sociedade, e força é reconhecer que muito ha ainda de empirico em tal ramo da actividade governamental.

3) Nas diversas definições do imposto, encontramos, não raro, a preoccupação de o justificar, ou de lhe dar os motivos philosophicos e politicos. Montesquieu disse que é "uma parte que cada cidadão dá de seus bens, 
para ver segura a outra, ou para desta gozar mais agradavelmente." Raynal, no mesmo sentido julga ser o imposto "sacrificio de uma parte de sua propriedade, para defesa da cutra." Dirigindo-se aos franceses, dizia Mirabeau: . "O imposto não é que um adiantamento, para obter a protecção da ordem social." 'Disse a Assembléa dever-se chamar imposto "a divida commum de todos os cidadáos e o preço das vantagens que a sociedade lhes traz." Com pico, explicou Voltaire ser "pagar o imposto, pôr uma parte de seus bens a servir a outra." Para Audiffret, imposto é o "saorificio pedido pela sociedade para a protecção de sua existencia, assim como para o desenvolvimento de seu poder." Emfim mencionarei Puynode para quem é o imposto "a parte que cada um põe na caixa commum para assegurar o gozo pacifico de seus bens e o respeito de sua pessoa." Nestas definições, o imposto é apresentado como sendo o premio de um seguro. Tal idéa é a que exprimem, com a maior clareza, Emilio Girardin e Proụdhon, segundo René Stourm, transcrevendo-lhes as proprias palavras: " $E$ ' a troca em que o Estado dá o serviço e o contribuinte, dinheiro; é, e não deve ser que um premio de seguro." Todas éstas definições peccam por excesso, visto como consideram apenas uma das funcções do imposto, qual a segurança de quem o dá: o imposto serve tambem para auxiliar o desenvolvimento dos fracos, e mesmo a acção dos fortes, pois, si a sociedade limita a liberdade, augmenta entretanto tambem as forças individuaes.

4) Repelle Stourm a idéa de que o imposto seja uma troca (idéa que transluz nessas definições) dizendo que, si eu pago impostos, é, não só para meu proveito, mas tambem de pobres, velhos, enfermos e desherdados. Ora, parece-nos que troca com equivalencia, no sentido de acto commutativo, não ha no imposto; mas equivalencia do ponto de vista aleatorio (e o proprio Codigo francês nos dá a equivalencia em actos aleatorios no art. 1104) 
ha no imposto, porque eu imagino que amanhan poderei cahir em desgraça, e precisar do auxilio do Estado, e eu tenho, além disso, este sentimento que Picard denominou progenismo, e que tão viva e vibrantemente descreveu em seu Direito Puro, ou sentimento de temor, de apprehensão, de inquietação pelo que possa succeder a meus descendentes. Ha pois no imposto uma troca, recebendo eu, ou djrectamente beneficios do Estado, ou a tranquillidade pelo que me possa acontecer, ou a meus descendentes. Póde o espirito sarcastico de Voltaire, citado por Stourm, fazer ver que o rustico é incapaz de comprehender isto, mas a limitação da intelligencia de alguns membros da sociedade, não tira o caracter de verdade aos principios scientificos, assim como a ignorancia das leis de Hygiene nos povos em estado rudimentar, como bem diz o dr. Lessa, não as aniquila.

5) Entretanto, força é reconhecer que à funcção. principal do imposto não é o seguro, não é a troca, tal como surge geralmente nas relações privadas. Elle apparece como sendo uma necessidade para a manutenção da socierlade, o que nos faz dar preferencia á definição de Graziani, quando o caracteriza com esse fim, que abrange todos os que lhe foram dados de troca, premio de seguro, adiantamento etc. Diz Graziani ser o imposto "quota de riqueza paga pelos particulares á communhão social e politica para consecução dos fins collectivos*" Nesta definição, apparece o fim do imposto em synthese, em resumo feliz, pois que lhe dá Garziani como funcção a realização do fim social, que é o progresso e o desenvolvimento. E' o imposto uma necessidade, assim como o é o Direito, força especifica do organismo social. Transparece ésta idéa no que dizem J. B. Say e Franklin. Para Say, o inposto é uma calamidade. Franklin dizia que ha duas coisas a que estamos todos sujeitos: morrer e pagar impostos. No mesmo sentido de Graziani, temos as definições de ou- 
tros mestres. Diz Leroy-Beaulieu: "Imposto é a contribuição exigida de cada cidadão por sua parte nas despezas do governo." Sustentou Adam Smith: "Imposto é a contribuição de todos os membros da sociedade, ou de uma parte desses membros ás despezas dos governos." Emfim citaremos Parieu que denomina "imposto o que o Estado toma das fortunas ou do trabalho dos cidadãos, para fazer face ás despezas públicas." Si preferirmos o ponto de vista realista, essas definições são até superiores á de Graziani, porque nem sempre as despezas a que são applicadas as contribuições tendem á conservação e ao desenvolvimento da sociedade. Do ponto de vista scientifico, querendo apresentar a verdadeira funç̧ão do imposto, é melhor a definição de Graziani. Pelas considerações que acabamos de fazer, e comquanto não tenhamos acceitado tudo quanto sustenta sobre o assumpto Stourm, nenhum motivo temos para repellir a definição que elle apresenta, onde a idéa de manutenção da sociedade é representada pelas expressões serviço público. Define elle o imposto: "L'impôt est un prélévement opéré sur les facultés individuelles des contribuables, pour subvenir aux dépenses des services publics."

6) Antes de entrar no estudo das vantagens e defeitos apresentados pelos diversos systemas de impostos, devemos distinguir os principios scientificos relativos aos impostos, das regras de tributar. A Sciencia das Finanças busca as verdades sobre o imposto; e a arte de lançar impostos, fundando-se nos conhecimentos fornecidos pela Sciencia das Finanças e por outras sciencias sociaes; determina como podem ser lançados os tributos com o minimo sacrificio individual. Darei exemplo, para tornar mais claro meu pensamento, e firmar bem este ponto, que é fundamental. Todos conhecemos as quatro regras de Adam Smith, de que devemos nos occupar, nesta pequena dissertação, regras que foram resumidas nas se- 
guintes palavras: justiça, certeza, commodidade e economia. Pois bem! A terceira, relativa á cobrança mais commoda, ou aos melhores processos e épocas para o recebimento, diz que "toda contribuição deve ser exigida na época e segundo as fórmas que pareçam mais commodas para o contribuinte." Por instincto, diz um mestre, sabe o fisco, segundo a comparação de Taine, a época em que a lan é mais abundante, para tosar o rebanho, Não se tracta ahi propriamente de instincto, como pretende o illustre mestre em Sciencia das Finanças. A verdade é que a sciencia, pela observação rigorosa da sociedade, chegou á conclusão de que, em certas occasiões, pagam os homens mais facilmente do que em outras. Determinou ainda a sciencia quaes essas occasiões, e o politico. utilizou-se de taes dados para estabelecer o tempo e a fórma de receber impostos. $\mathrm{O}$ imposto deve ser cobrado. dos herdeiros no momento em que receberem a quota hereditaria e antes de entrarem no gozo dessa quota; o imposto sobre os vencimentos deve ser abatido delles, ao tempo do pagamento do funccionario, evitando assim o fisco ter de recorrer a meios judiciaes, onerosos e de menor efficacia que o desconto; o imposto sobre o rendimento dos capitaes deve ser cobrado no momento em que, em geral, recebem os capitalistas esse rendimento. Mas, a par deste princ1pio scientifico, revelado ou descoberto pela Sciencia das Finanças, surgem outros que influem sobre as regras artisticas de tributar, como facilmente mostraremos. Si a patria corre perigo, nos casos de guerra a emprehender, ou ıos casos de necessidade de pagamento de indemnização de guerra, já os principios de outras sciencias sociaes exigem que se attenda á necessidade de manter a communhão social, de a defender, e o principio da maior facilidade de percepção de impostos passa a segundo plano, como facilmente se póde ver na dolorosa noticia que nos dá o Diccionario das Finanças de Léon Say, ao tractar das indemnizações de guerra recebidas, e das pagas, pela 
França no curso do seculo XIX, não se esquecendo o autor do "Vae victis" de Brenno. Ainda ahi, porém, o Estado moderno busca o minimo do sacrificio para os contribuintes, mas o sacrifieio será maior sempre que o de épocas normaes. Com essas noções, podemos passar ao estudo dos principios scientificos fundamentaes, em matéria de impostos, para depois vermos os secundarios, derivados dos cardeaes; e finalmente occupar-nos-emos das regras artisticas relativas á fórma por que devem ser lançados os tributos.

7) Stuart Mill deu como principio fundamental do imposto o da equivalencia (principle of equal sacrifice), ou contribuição de cada um na 'medida de suas forças, principio que não se deve confundir com o da equivalencia do que dá o contribuinte e do que recebe do fisco.

Contra este principio está Nitti, sustentando que é muito difficil definir o que é a equivalencia do sacrificio. Entretanto reconhece Nitti que esse principio exerce na legislação positiva um estimulo para a justiça, e é antes um limite do que um methodo. Não tem razão, cremos, Nitti, contra o genial philosopho inglês. Todo principio fundamental é vago, cabendo aos principios secundarios: determinal-o, como ensinam o proprio Mill em sua Logica e Alexandre Bain. Si servir, como tem servido, de norte ao legislador, digno deste nome, o principio de Mill póde ser considerado como havendo produzido o que é requerido pela sciencia. Ainda é fundamental o principio. estabelecido por Edgeworth, e de que falei linhas acima, qual o do menor sacrificio (least sacrifice). A estes dois principios fundamentaes, eu ajuntaria emfim, como sendo cardeal, o que inspirou a quarta regra de Adam Smith, a saber que o imposto seja o mais productivo possivel. Assim poderia dizer, á semelhança do que se diz da pena, outro mal necessario, que o imposto deve dar o maximo do proveito com o minimo do sacrificio para o individuo.

19 - Revista F. D. 
traduzindo o que a tal respeito disseram Stuart Mill, Edgeworth e Adam Smith. Foram os principios que nos pareceram primordiaes, ou fundamentaes, comprehendendo todos os outros. Poder-se-á citar como sendo um dos principios fundamentaes ou irreductiveis, o da precisão ou exactidão da importancia tributada que inspirou a primeira regra de Adam Smith. Ora este requisito do imposto é meramente juridico, relativo á lei que o lança, e portanto não é dominado pelos principios da Sciencia das Finanças. O jus certum é preoccupação do Direito e particularmente do Direito Constitucional, como se vê no art. $72 \S 30$ da Constituição Federal. Si é certo que, no lançar impostos, deve se ter em vista o principio da fixidade, força entretanto é reconhecer que este principio de natureza juridica não deve ser levado a extremo, de modo a tirar toda a elasticidade politica ao systema de tributos de um paiz. Cumpre harmonizar os dois principios. Diz. Wagner, illustre professor na universidade de Berlim: "O principio da elasticidade ou da mobilidade (Beweligchkeit) significa que a imposição deve, ao menos, conter os elementos ou categorias que possam se adaptar ás variações das necessidades financeiras,... e fazer face aos deficits eventuaes." Wagner tem um systema que nos pareceu em extremo complicado. Para elle, os principios superiores num systema de impostos, são 9, distribuidos em 4 grupos. 0 grupo de politica financeira comprehende dois principios: sufficiencia e elasticidade, o de economia publica, os principios de escolha de boas fontes de tributos, escolha de classes de impostos, ligando grande importancia á repercussão dos impostos. O grupo da equidade ou equitativa repartição dos impostos, abrange os principios da generalidade e uniformidade dos impostos. Os principios que formam o grupo dos relativos á administração fiscal, são os da fixidade, commodidade e tendencia a reduzir o mais possivel a percepção dos imposios. Parece-nos que esses principios de Wagner se 
reduzem aos tres fundamentaes que acabamos de apresentar.

8) $\mathrm{Na}$ busca do melhor systema de tributar, ou que menor sacrificio imponha aos contribuintes, querem uns escriptores o systema do imposto unico, outros o do imposto multiplo. O imposto unico, conforme mostraram Leroy Beaulieu, Nitti e outros só seria possivel em um paiz, cuja receita não fosse elevada. Dado o imposto sobre a terra, que é, pela escola physiocrata de que faziam parte Quesnay e Turgot, o unico factor da verdadeira riqueza produzida pela industria agricola, o resultado seria a necessidade em que se achariam os proprietarios da terra de elevar o preço de seus productos. Como porém o valor é regulado pela lei da offerta e da procura, claro é que os compradores iriam buscar em paiz estrangeiro os objectos de que precisassem. Tal imposto, pois, só seria possivel, si fosse tão pouco elevado que correspondesse ao preço de transporte dos productos e ás demais despezas de importação, quando já Quesnay julgava necessario que fosse do terȩo do producto da terra. Hoje de quanto seria; augmentadas as despezas publicas!... Foi ésta a consequencia entrevista por Voltaire, ao escrever seu .celebre conto "Homem de 40 escudos", citado e transcripto por Leroy Beaulieu, Nitti e outros. Antes, porém, dos physiocratas, observa Nitti, já alguns grandes homens que se occupavam com a felicidade publica haviam preconizado o imposto unico. Bodin sustentava só deverem ser conservados os impostos de alfandega. Vauban, em sua obra Dizimo Real, queria um imposto unico geral, e certos impostos indirectos pequenos. Boisguillebert pretendia fossem abolidos quasi todos os impostos, mantendo-se unicamente os referentes a immoveis. Modernamente, diz Leroy Beaulieu, ha os partidarios do imposto on real property, que são numerosos.

Nos Estados Unidos, ha ainda os partidarios do imposto unico sobre o capital fixo, doutrina de que é ardente 
partidario o industrial Ménier. Como se vê, o imposto: unico sobre a terra, defendido pelos physiocratas, entre os quaes se achava Le Mercier de la Rivière, defensor da doutrina de que o Estado é, por Direito Divino, coproprietario da terra, não passa de um episodio neste furor de simplificação. Ésta simplificação, porém, é impossivel, como mostrou Baudrilart, fazendo sentir que a complexidade crescente da vida social se oppõe a tal sonho: “Ni la science, ni la société moderne ne s'accommodent de cette unité abusive, de cette simplicité extrême, de cette. logique à outrance. Tout s'est compliqué en réalité. Comment vouloir réduire à l'unité absolue cette multiplicité qu'on trouve dans les faits accumulés par l'observation?" Celebre se tornou tambem a phrase caustica de Proudhon que entendia ser o imposto unico "it somma das iniquidades fiscaes, um imposto de uma iniquidade prodigiosa, de iniquidade ideal, pois que teria por effeito pôr mais violentamente em relevo a anomalia commum a cada especie de imposto, anomalia que se sente e se vê tanto menos quanto mais se reparte."

9) Mas porque é hoje o imposto unico defendido. pelos socialistas? Si é a monstruosidade descripta por Proudhon e Voltaire, como encontra defensores entre os que se dizem protectores das classes que se acham, ou se julgam opprimidas, das classes fracas? $O$ motivo não é difficil de ser encontrado. E' que imaginam esses modernos socialistas que, com o imposto unico, conseguirão a nacionalização da terra, e essa nacionalização lhes parece trazer a felicidade ao mundo moderno. Nacionalizada a terra, teria o imposto unico sobre ella deixado de ter razão, por ter cumprido seu destino. Seria pois, tal qual é hoje preconizado pelos socialistas, um imposto de transição, uma arma de combate usada accidentalmente.

10) Em opposição ao imposto unico, fala o saudoso dr. Veiga Filho em systema de multiplicidade de 
impostos e de pluralidade de impostos, reportando-se ao que ensina Leroy Beaulieu. Historicamente tem razão o dr. Veiga, que bem traduziu o pensamento do grande escriptor francês, pois houve Arthur Young e Cornewall Lewis que sustentaram que, quanto maior for o numero de impostos, melhor será o systema financeiro. Tal these porém não encontra explicação, defesa, e é ella portanto, elevar a principio scientifico o empirismo. Scientificamente o systema que se oppõe ao do imposto unico é sómente o da pluralidade de impostos, ou da multiplicaçāo dos impostos de accôrdo com as necessidades sociaes, mas buscando, como diz Leroy Beaulieu, a "simplicidade e concentração."

11) Imposto proporcional ou progressivo? Com razão observa Stuart Mill que, "partindo do principio de que se deve pedir a cada individuo um sacrificio igual, temos a indagar si esse principio estaria respeitado no caso de dar cada um uma mesma porcentagem sobre seus rendimentos." Parece-nos que sim, que ésta será a regra. Entretanto a solidariedade que reina na sociedade, a necessidade de integração reciproca, eis um motivo para pôr limite ao absoluto da proporção, e motivo para exigir que, por considerações de justiça de proteç̧ão aos fracos, surja o principio de progressão no imposto, e o de isenção, favorecendo os entes mais fracos, que devem tambem gozar dos beneficios da vida em sociedade.

O imposto progressivo é uma excepção, dissemos, e, explicando nosso pensamento, diremos que nasce de principios politicos, tomando o aspecto de imposto destinado a dirigir forças sociaes em proveito da mesma sociedade, funcção accidental do imposto de que nos occuparemos mais abaixo. Si effectivamente ha vantagem na limitação da fortuna social (e este não é problema que pertença á Sciencia das Finanças), si é o mais feliz Estado aquelle em que menor differença existe entre as fortunas dos seus 
diversos membros, o imposto progressivo deve ser preferido como medida politica, para diminuir essa differença, sem buscar propriamente o nivelamento. 0 imposto progressivo deve ter certa moderação, si a Politica aconselhar que não sejam estancados os estimulos dos mais activos. e industriosos membros da communhão social. Vae pois o imposto progressivo buscar seu motivo, sua causa, sua razão de ser, na Politica. A Sciencia das Finanças nada mais faz do que traçar os processos technicos para lhe moderar a acção niveladora. Dahi o imposto digressivo, dahi outras combinações ideadas para lhe abrandar os effeitos. Si por uma parte, temos de limitar o desenvolvimento excessivo das fortunas, por outra, póde a Philosophia Juridica, em sua funcção geralmente denominada prática, ou na determinação dos ideaes sociaes, mostrar a necessidade de, em assistencia ás classes mais fracas, limitar a certa renda o onus de contribuição, isentando de impostos os rendimentos em extremo diminutos. São outros estudos sociaes que não o das Finanças, é ainda tambem a Politica que determinam quaes as classes que devem ser isentadas de tributos, ou ter, ao menos, contribuição accentuadamente mais leve. A Sciencia das Finanças nada mais faz do que estudar, de mãos dadas com a Economia Politica, os effeitos dessas isenções. Não queremos com isto dizer que as doutrinas sobre finanças sejam organizadas com desprezo da preoccupação de moralidade. Isola-se o estudo das finanças para maior commodidade, mas pede a Sciencia das Finanças subsidios ás demais sciencias sociaes. Firma, como sendo ideal, a equivalencia dos sacrificios, considera este principio um dos fundamentaes, mas porque, conforme ensina Stuart Mill, este principio, cardeal em Sciencia das Finanças, é consequencia do principio da igualdade que domina todas as sciencias governamentaes. Mas a igualdade formal, explicam Ahrens e os demais mestres, só existe com a desigualdade material ou concreta. 
12) Ao lado destes principios fundamentaes, fecundos em regras práticas, devemos considerar as proprias regras, e dellas as mais dignas de exame são as de Adam Smith, ás quaes por vezes temos nos referido neste modesto e fugidio trabalho. Logo após esse exame, mostraremos que muitas modificações soffrem ellas em sua applicação aos diversos povos, de accôrdo com as necessidades que são peculiares a taes povos, segundo explica Nitti, resumindo a solução do problema que, neste trabalho, nos occupa. A primeira regra é que os membros de uma communhão social devem pagar os impostos na proporção de suas faculdades, ou segundo a renda que tiverem. E' o principio da justiça ou da igualdade que inspira ésta regra. Já dissemos quanto á isenção pela impossibilidade de pagamento por parte de alguns membros beneficiados pelos laços de solidariedade social. A segunda regra é que se determine o imposto, quer quanto ao valor, quer quanto á época de pagamento, quer quanto ao modo de pagamento, para se evitar o arbitrio dos exactores. Attende-se á certeza, ao formular ésta regra. Ella se inspira no principio do minimo sacrificio, a que acima nos referimos (principle of least sacrifice).

Ainda a terceira regra que manda cobrar os impostos nas épocas e na fórma que forem mais commodas para o contribuinte, ou regra da commodidade, é inspirada no principio do menor sacrificio. A quarta regra que recommendá seja o tributo cobrado com a maior economia, é, como dissemos, linhas acima, resultado do terceiro principio fundamental que apresentámos, a saber: de produzir o imposto o mais possivel. Classicas são taes regras de Smith, e sua maior importancia vem dos commentarios que lhe foram feitos, já pelo proprio autor, quando lhes explicou o sentido, já por homens da estatura de Stuart Mill.

Aos tres principios fundámentaes, porém, que acima apresentámos, se reduzem não só essas regras, mas tam- 
bem as que, para as completar, apresentam Stuart Mill, Réné Stourm, Alberto Delatour, Jèze e outros.

13) Uma outra questão geral sobre impostos é a que se traduz na pergunta: deve o imposto ser instrumento de estimulo ao trabalho, de protecção a certas industrias, de moralização? E' bom precisar melhor a questão. Não se pergunta si o imposto deve ser moralizado, justo, mas si deve moralizar; si não deve matar a iniciativa individual, mas si deve ser principalmente destinado a estimular o individuo ao trabalhó, a auxiliar certas industrias. Nós resumiriamos as locuções imposto moralizador, imposto para a hygiene, para proteger industrias, para tornar o povo trabalhador, nesta unica - imposto de cultura, tendo presente uma das fundamentaes funcções do Estado moderno. Tractaremos da questão. Que o imposto seja estimulo ao trabalho (imposto estimulante) é paradoxo dos que se encontram em todas as sciencias. Os impostos, quando excessivos, matam a industria, e geram o desespero, ccmo ensina Hume, e quando moderados, de nenhum modo formam o espirito laborioso nos contribuintes. Que o imposto possa proteger progressivamente certas industrias, impossivel é de contestar, não obstante o máu resuliado quando erradamente usado por financeiros ineptos. Que possa auxiliar a Politica como sendo uma força de que dispóe o Governo para a hygiene, moralização do povo etc., não nos parece se deva pôr em duvida. A difficuldade está em comprehender o politico a arma de.que dispóe, e saber como a deverá dirigir em proveito da sociedade que governa. Assim, para saber si convém fortemente tributar as heranças, deverá o politico indagar antes si é bom manter ou atacar as grandes fortunas transmittidas por successão mortis causa; para saber si deve lançar pesados impostos nos artigos de luxo, deverá conhecer préviamente a solução a dar á questão contro. vertidissima do luxo... Isto posto, diremos que o im- 
posto deve ser sempre inspirado nos principios da justiça, mas que nada impede que seja dirigido como arma politica para o governo de um Estado conseguir certos resultados. Firmaremos porém que o imposto é filho da necessidade social de dar á communhão social meios de subsistir, e não gerado do intento de cultura do povo pelo governo. Modificando a phrase de Flanklin que citámos no começo desta dissertação, diremos que os beneficios da sociedade exigem de nós dois sacrificios: a restricção de nossa liberdade e o pagamento de impostos.

Não deixaremos ésta matéria, sem recordar a aguda critica feita por Jèze á doutrina dominante no seculo XVIII, de que o imposto é um bem, porque constitue um estimulo á producção (un aiguillon à la production), doutrina contestada por David Hume.

Referem Jèze, Leroy Beaulieu e outros que Mac Culloch cita, o caso do aperfeiçoamento dos alambiques para fugirem os contribuintes ao imposto. Faz Jèze sentir que não foi o imposto que estimulou o espirito inventivo, mas a possibilidade de fugir ao seu pagamento. Como sabemos, não raro impostos mal lançados levam ao contrabando, e disto temos exemplos nos aduaneiros do Rio Grande do Sul. Quando o imposto é de natureza a impedir as evasões, não póde excitar o espirito industrioso dos contribuintes, determinando melhoramentos no processos industriaes.

Não cabe nos limites deste breve trabalho dizer mais sobre ésta interessantissima questão.

14) Tractámos de dar os principios fundamentaes do melhor systema tributario, estabelecemos os principios derivados desses, e as regras artisticas resultantes da applicação das verdades scientificas ás relações sociaes, á vida social.

Resta-nos dizer quaes as outras partes componentes do melhor systéma. Inutil e até enfadonho é repetir que 
não se deve procurar um bom systéma, mas o melhor, ou antes o menos imperfeito. $\mathrm{O}$ grande mestre Nitti, em um capitulo em que estuda os varios systemas de impostos, mostra que divergem muito taes systemas segundo as condições de riqueza dos povos a que são applicados. Analysa os systemas tributarios da Inglaterra, da França, da Allemanha, da Austria, da Hollanda, da Italia, da Russia, fazendo sentir que essas nações adoptaram empiricamente os systémas que melhor se adaptavam ás suas condições economicas e politicas. Impostos directos ou indirectos reaes ou pessoaes, isenções, impostos de cultura, impostos progressivos, tudo depende das condições especiaes de cada paiz. "Tout pays, repetiremos a citação que fizemos no meço desta dissertação, a sur ce point, on peut le dire, ses institutions particulières; chacun assigne aux divers impôts une fonction différente, selon le dégré de developpement économique qu'il a atteint. Les finances publiques trouvent des rapports existants et qu'elles ne peuvent changer, elles revêtent donc, dans chaque pays, des formes spéciales. Les finances des pays riches diffèrent complètement de celles des pays pauvres; les finances des pays industriels de celles des pays agricoles; les finances des pays dans les quels la richesse est concentrée de celles des pays où elle est fractionnée." (Trad. de Charmard).

Não encerraremos este insignificante trabalho, sem lembrarmos que o peso dos impostos não é tão perigoso quanto a má distribuição e cobrança delles. Por pouco que se conheça a historia da revolução francesa, ha de se ver quão verdadeiras são éstas palavras: "C'est contre l'arbitraire, spécialement que se sont élèvées les récriminations des cahiers de 1789 , pour aboutir à la transformation de notre système fiscal." Franklin, o notavel e prudente Franklin, ao dar as regras para tornar pequeno um grande imperio, dizia que um dos processos é dar aos exactores elevadas remunerações, de modo que vivam em insultuoso luxo, tirado do suor e do sangue do povo 
laborioso, povo que esses exactores perseguem com suas exigencias vexatorias e dispendiosas. A questão pois que occupou nossa attenção é das que mais de perto interessam ao desenvolvimento e felicidade de um povo, e sentimos que forças nos faltem para melhor della tractar, determinando o que exigem as condiçóes de nossa patria, para que tenha um dos menos imperfeitos systemas tributarios, guardados os tres principios fundamentaes a serem respeitados por todo systéma de impostos, que não quizer violar as leis scientificas, e ser damnoso á vida social.

Podemos dizer, terminando, que o melhor systéma é o que, respeitando os principios de igualdade, e minimo sacrificio, dê o maximo do proveito, e melhor se adapte ás condiçõe peculiares do povo para que foi instituido.

Braz de Sousa Arruda. 